in vivo $33: 979-982(2019)$

doi:10.21873/invivo.11567

\title{
Malnutrition and Survival - Bioimpedance Data in Head Neck Cancer Patients
}

\author{
JUDITH BÜNTZEL ${ }^{1}$, OLIVER MICKE $^{2}$, KLAUS KISTERS $^{2}$, JENS BÜNTZEL ${ }^{2,3}$ and RALPH MÜCKE ${ }^{2}$ \\ ${ }^{1}$ Department of Hematology, Medical Oncology, University Hospital Göttingen, Göttingen, Germany; \\ ${ }^{2}$ German Study Group 'Trace Elements and Electrolytes in Oncology' (AKTE), Bielefeld, Germany; \\ ${ }^{3}$ Department of Otolaryngology, Head Neck Surgery, Südharz Hospital, Nordhausen, Germany
}

\begin{abstract}
Background/Aim: Bioimpedance analysis (BIA) reflects the nutritional status of patients. The aim of this study was to examine whether BIA is able to document the possible impact of malnutrition on survival. Materials and Methods. The registered data of 42 head and neck cancer patients were analyzed. Survival data of 22 women and 20 men were included. The mean age was $67.3 \pm 10.77$ years. BIA was measured by the Biocorpus 4000 RX (MEDIcal Health Care $\mathrm{GmbH}$ Karlsruhe) and summarized in individual phase angle (PA) of each patient. Results: Patients with normal PA>5.0 had a significantly better survival $(p=0.016)$. The median survival time was 13.84 months (range=0.69-125.19 months) in malnourished patients $(P A<5.0)$ compared to 51.16 months (range=7.02-116.79 months) in normally nourished head and neck cancer (HNC) patients (PA>5.0). Age adjusted body mass index had a similar impact on prognosis, but was not statistically significant $(p=0.068)$ in the investigated study groups. Conclusion: BIA is able to document the impact of malnutrition on the survival of head and neck cancer patients.
\end{abstract}

Malnutrition is a great problem for head and neck cancer patients. The majority of them are already suffering from a bad nutritional status at the time of diagnosis (1). About $90 \%$ will develop additional symptoms such as dry mouth, loss of taste, loss of appetite, nausea and vomiting as a consequence of anti-cancer therapy. Furthermore, a third of all patients will develop late toxicities such as xerostomia and fibrotic stenosis, which disturb normal eating for the rest of their life (2).

This article is freely accessible online.

Correspondence to: Judith Büntzel, MD, Department of Hematology and Medical Oncology, University Hospital Göttingen, Robert-Koch-Str. 40, 37075 Göttingen, Germany. Tel: +49 551 3966327, e-mail: judith.buentzel@med.uni-goettingen.de

Key Words: Malnutrition, bioimpedance analysis, head and neck cancer, body mass index, prognosis.
Until today, nutrition was a central theme among cancer patients and their physicians. Screening tools such as the NRS 2002 or the MUST Score are using standardized questions or global information regarding general appearance $(3,4)$. Sometimes laboratory data regarding total protein or albumin are used to describe malnutrition (5).

There is need to develop tools to objectively measure malnutrition, cachexia or sarcopenia . The oldest marker of nutritional status is age-adjusted body mass index (BMI) $(6,7)$. However, BMI has a low sensitivity to recognize malnourished patients. Anthropometric data like skin fold measurements and dynamic hand craft are also able to describe body status, e.g. malnutrition as a complex phenomenon (8-10).

In order to better characterize body composition or muscle mass, more invasive methods such as DEXA, CT or bioimpedance-analysis-based measurements should be used (11).

This study investigated the possible advantages of bioimpedance analysis (BIA) in comparison to age-adjusted body mass index in advanced head and neck cancer patients.

\section{Patients and Methods}

Patients suffering from head and neck cancer were included into a non-interventional, anonymous, mono-institutional, retrospective register study. Treatment and follow-up performed at the department of ENT Diseases, Head Neck Surgery of the Südharz Hospital Nordhausen between 2008 and 2018.

Treatment included surgery and additional radiotherapy or primary radiochemotherapy in all patients. The follow-up visits were performed bi-monthly during the first 2 years and every 6 months thereafter.

Under therapy and/ or follow-up, BIA of all patients was measured by Biocorpus 4000 RX (MEDIcal Health Care GmbH Karlsruhe). BIA yielded reactance and resistance as raw data, both were required to calculate PA. The individual PA and additional anthropometric measurements (body length, body mass) of each patient were obtained at the time of BIA by qualified staff.

Information on overall survival was extracted from follow-up files. At first, the study population was divided into two groups$\mathrm{PA}<5^{\circ}$ and $\mathrm{PA}>5^{\circ}$. Afterwards PA and overall survival were used for Kaplan-Meier calculations performed using MS excel and an add- 
in [Cs_Dbp_Km, University of Halle, (12)]. Secondly, the same analysis was performed for a BMI less or more than $23 \mathrm{~kg} / \mathrm{m}^{2}$.

A phase angle $(\mathrm{PA})>5.0$ and a $\mathrm{BMI}>23.0 \mathrm{~kg} / \mathrm{m}^{2}$ defined normal nutritional status for patients older than 55 years.

All research was performed in accordance with the actual version of declaration of Helsinki. No further ethical approval was necessary because this observational study was anonymous and noninterventional.

\section{Results}

A total of 42 patients suffering from head-neck cancer were included in this retrospective observational study (for patient characteristics refer to Table I). Cancer entities were heterogeneous: oropharyngeal carcinoma $(n=15)$, laryngeal cancer $(n=7)$, oral cancer $(n=5)$, hypopharyngeal carcinoma $(n=4)$, neoplasm of the salivary glands $(n=4)$, others $(n=7)$. The histology of all samples was squamous cell carcinoma of the head and neck region. The standard of treatment was similar - surgery plus adjuvant radio(chemo)therapy.

A total of $24 / 42(57.1 \%)$ patients were normally nourished $\left(\mathrm{PA}>5^{\circ}\right), 11$ patients had a high-risk for malnutrition (PA $4^{\circ}$ $5^{\circ}$ ) and 7 patients were malnourished $\left(\mathrm{PA}<4^{\circ}\right)$.

A total of $19 / 42(45.2 \%)$ patients had a body mass index lower than the age adapted norm $\left(<23.0 \mathrm{~kg} / \mathrm{m}^{2}\right)$.

Patients with a $\mathrm{PA}>5^{\circ}$ showed a significantly better overall survival ( $\mathrm{p}=0.016$; Figure 1). Median survival in this group was 51.16 months (range=7.02-116.79 months), while median survival of malnourished patients was 13.84 months (range=0.69-125.19 months). BMI was similar in both patient groups; no significant difference was found (Table I).

Patients with BMI $>23.0 \mathrm{~kg} / \mathrm{m}^{2}$ had a better overall survival $(\mathrm{p}=0.068)$. As shown in Figure 2, patients with a normal BMI live for a median of 55.66 months (range $=7.02$ 125.19 months) compared to 14.89 months (range $=0.89$ 82.98 months) for patients with $\mathrm{BMI}<23 \mathrm{~kg} / \mathrm{m}^{2}$. Table II summarizes the biometric data of the BMI subgroup analysis.

\section{Discussion}

In 2017, the European Society of Parenteral and Enteral Nutrition (ESPEN) published the last version of a consensus paper on the definition of cachexia and malnutrition. Unexpected weight loss, and decreased BMI are listed as main criteria. Reduced fat free mass was added as a new parameter. No consensus was reached regarding which method is the best for evaluating malnutrition (13).

Bioelectrical impedance analysis is an established method in diagnosing sarcopenia or malnutrition of cancer patients (14-16). The PA is a summarized central parameter to classify BIA's measurements (17) used in previous studies to assess malnutrition in head and neck cancer (HNC) patients (18).
Table I. Biometric data, sub-analysis according to BIA phase angle (PA)

\begin{tabular}{lccc}
\hline & Total & PA $<5.0$ & PA $>5.0$ \\
\hline Number & 42 & 18 & 24 \\
Male & 20 & 8 & 12 \\
Female & 22 & 10 & 12 \\
Age $($ a $)$ & 67.29 & 66.81 & 67.66 \\
SD & 10.77 & 10.79 & 10.74 \\
BMI $\left(\mathrm{kg} / \mathrm{m}^{2}\right)$ & 23.69 & 22.13 & 24.86 \\
SD & 3.40 & 3.44 & 2.86 \\
$\mathrm{~N}$ BMI $\leq 23 \mathrm{~kg} / \mathrm{m}^{2}$ & 19 & 11 & 8 \\
$\mathrm{~N}$ BMI $>23 \mathrm{~kg} / \mathrm{m}^{2}$ & 23 & 7 & 16 \\
Median survival $(\mathrm{mo})$ & 42.08 & 13.84 & 51.16 \\
Range & $0.69-125.19$ & $0.69-125.19$ & $7.02-116.79$ \\
\hline
\end{tabular}

Table II. Biometric data, sub-analysis according to body mass index (BMI).

\begin{tabular}{lccc}
\hline & $\begin{array}{c}\text { Total } \\
<23 \mathrm{~kg} / \mathrm{m}^{2}\end{array}$ & $\begin{array}{c}\text { BMI } \\
>23 \mathrm{~kg} / \mathrm{m}^{2}\end{array}$ & BMI \\
\hline Number & 42 & 19 & 23 \\
Male & 20 & 8 & 12 \\
Female & 22 & 11 & 11 \\
Age $($ a) & 67.29 & 63.43 & 70.48 \\
$\mathrm{SD}$ & 10.77 & 12.80 & 7.99 \\
$\mathrm{PA}\left({ }^{\circ}\right)$ & 5.17 & 4.95 & 5.36 \\
$\mathrm{SD}$ & 1.13 & 1.01 & 1.21 \\
$\mathrm{~N}$ PA $<5.0^{\circ}$ & 19 & 11 & 8 \\
$\mathrm{~N}$ PA $>5.0^{\circ}$ & 23 & 7 & 16 \\
Median survival (mo) & 42.08 & 14.89 & 55.66 \\
Range & $0.69-125.19$ & $0.69-82.98$ & $7.02-125.19$ \\
\hline
\end{tabular}

We observed that a PA $<5^{\circ}$ was a sufficient threshold for identifying HNC patients with a shorter median survival. These results correspond to a study of patients undergoing cardiac surgery, where a $\mathrm{PA}<4.5^{\circ}$ was indicative for a higher frailty and mortality (19). Another study on palliative care patients suffering mainly from gastric cancer set the PA threshold at $<4^{\circ}$. Interestingly, in this study, patients with a $\mathrm{PA}>4^{\circ}$ showed a nearly twofold increase in median survival time (20). Furthermore, a study with a patient cohort similar to ours proposed that a cutoff value of $5.95^{\circ}$ provides the best prediction of 5-year survival in patients with HNC (21). In accordance to these previously published studies, our results indicate that BIA is a sensitive marker for identifying patients at risk.

BMI is influenced by age; generally a slightly higher BMI is recommended in the elderly $(6,7)$. Therefore, a BMI threshold of $23 \mathrm{~kg} / \mathrm{m}^{2}$ was chosen. There was a trend towards longer survival in patients with a BMI $>23 \mathrm{~kg} / \mathrm{m}^{2}$. 


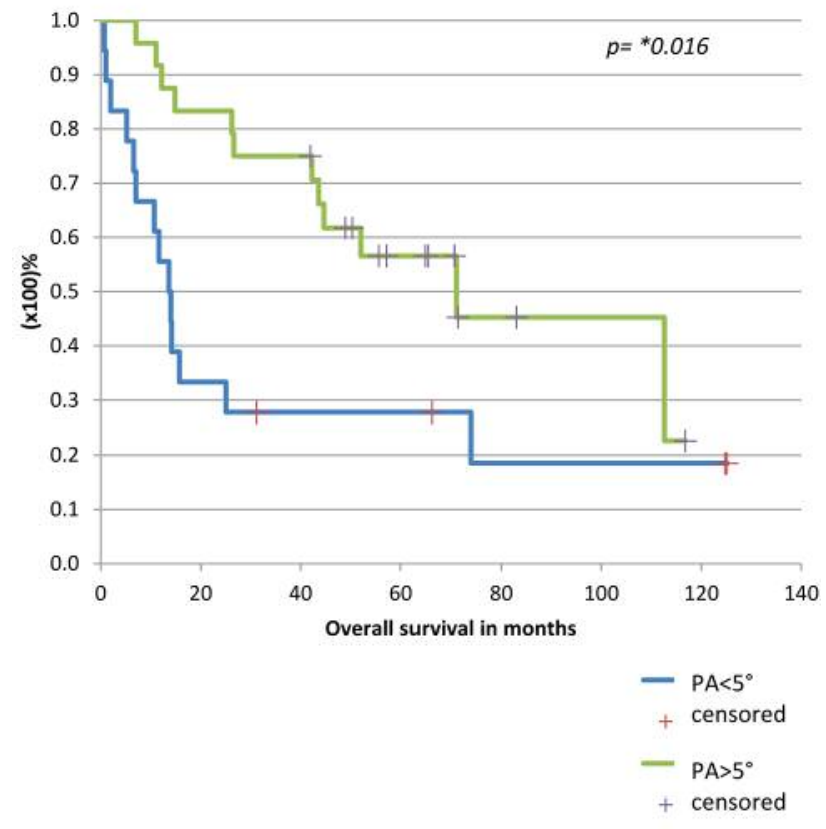

Figure 1. Overall survival (Kaplan-Meier) according to BIA phase angle $(p=0.016)$.

Noticeably, even age-adjusted BMI did not detect seven patients with a $\mathrm{PA}<5^{\circ}$. While four of these patients were only at increased risk, three were malnourished $\left(\mathrm{PA}<4^{\circ}\right)$. On the other hand, age adjusted BMI detected eight patients with a $\mathrm{PA}>5^{\circ}$. Considering that patients with a $\mathrm{BMI}<23 \mathrm{~kg} / \mathrm{m}^{2}$ showed a trend towards a shorter overall survival, this subgroup of patients also seems to be at risk. This argues for combining both parameters.

This small mono-institutional study indicates the need to establish diagnosis of nutritional status in a different manner. Anamnestic tools would be Nutritional Risk Score (NRS) 2002 or MUST $(3,4)$. The measurement of body mass and body length has to be a minimum standard in each oncology department. In addition, bioimpedance analysis and calculation of age-adjusted body mass index should also be performed before interpretation.

Focusing on head and neck cancer patients, malnutrition has to be treated as early as possible. Early integration could improve the outcome of standard treatment. Similar concepts are known from fast-track surgery for other cancer patients. A former study has indicated a better outcome from radiotherapy if patients have had early energy substitution (22).

\section{Conflicts of Interest}

There are no conflicts of interest to declare regarding this study.

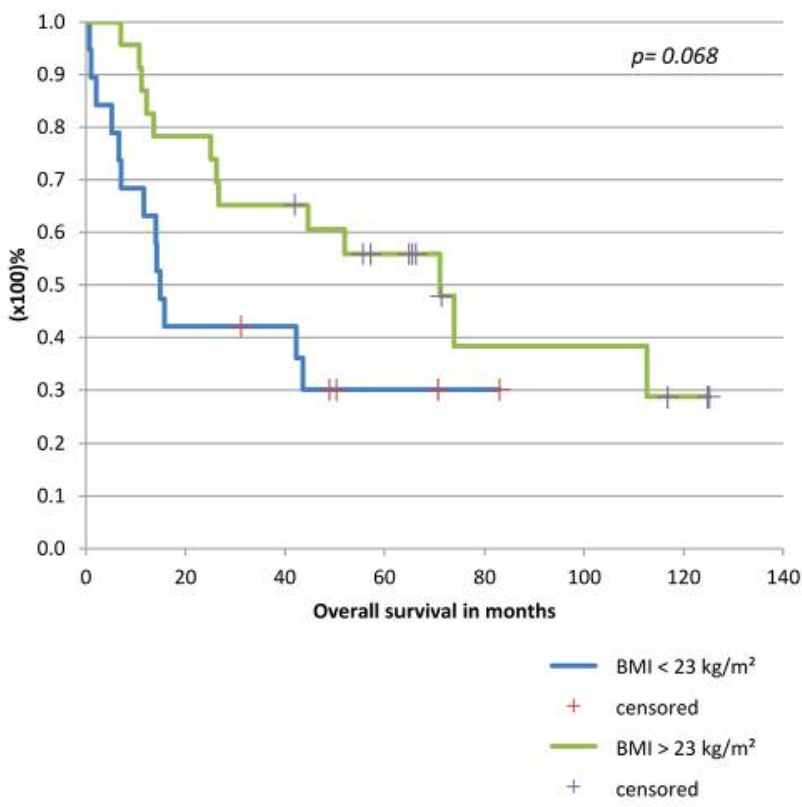

Figure 2. Overall survival (Kaplan-Meier) according to age-adjusted $B M I(p=0.068)$.

\section{Authors' Contributions}

Judith Büntzel: data analysis, writing, editing; Oliver Micke: conceptualization; Klaus Kisters: supervising; Jens Büntzel: data sampling, data analysis; Ralph Mücke: supervising.

\section{References}

1 Müller-Richter U, Betz C, Hartmann S and Brands RC: Nutrition management for head and neck cancer patients improves clinical outcome and survival. Nutr Res NY N 48: 1-8, 2017. PMID: 29246276. DOI: 10.1016/j.nutres.2017.08.007

2 Büntzel J, Glatzel M, Mücke R, Micke O and Bruns F: Influence of amifostine on late radiation-toxicity in head and neck cancer-a follow-up study. Anticancer Res 27: 1953-1956, 2007. PMID: 17649803.

3 Elia M: The "MUST" report. Nutritional screening for adults: a multidisciplinary responsibility. Development and use of the "Malnutrition Universal Screening Tool" (MUST) for adults., 2003. Available from: https://eprints.soton.ac.uk/362499/[last accessed February 10, 2019].

4 Kondrup J, Rasmussen HH, Hamberg O, Stanga Z and Ad Hoc ESPEN Working Group: Nutritional risk screening (NRS 2002): A new method based on an analysis of controlled clinical trials. Clin Nutr Edinb Scotl 22: 321-336, 2003. PMID: 12765673.

5 Arends J, Bachmann P, Baracos V, Barthelemy N, Bertz H, Bozzetti F, Fearon K, Hütterer E, Isenring E, Kaasa S, Krznaric Z, Laird B, Larsson M, Laviano A, Mühlebach S, Muscaritoli M, Oldervoll L, Ravasco P, Solheim T, Strasser F, de van der 
Schueren M and Preiser J-C: ESPEN guidelines on nutrition in cancer patients. Clin Nutr Edinb Scotl 36: 11-48, 2017. PMID: 27637832. DOI: 10.1016/j.clnu.2016.07.015

6 Yi SW, Ohrr H, Shin SA and Yi JJ: Sex-age-specific association of body mass index with all-cause mortality among 12.8 million Korean adults: A prospective cohort study. Int J Epidemiol 44: 1696-1705, 2015. PMID: 26208807. DOI: 10.1093/ije/dyv138

7 Adolph M: Ernährungsmedizin: Nach dem neuen Curriculum Ernährungsmedizin der Bundesärztekammer; 276 Tabellen. Georg Thieme Verlag, 2010.

8 Beaudart C, McCloskey E, Bruyère $\mathrm{O}$, Cesari $\mathrm{M}$, Rolland $\mathrm{Y}$, Rizzoli R, Araujo de Carvalho I, Amuthavalli Thiyagarajan J, Bautmans I, Bertière M-C, Brandi ML, Al-Daghri NM, Burlet N, Cavalier E, Cerreta F, Cherubini A, Fielding R, Gielen E, Landi F, Petermans J, Reginster JY, Visser M, Kanis J and Cooper C: Sarcopenia in daily practice: Assessment and management. BMC Geriatr 16: 170, 2016. PMID: 27716195. DOI: $10.1186 / \mathrm{s} 12877-016-0349-4$

9 Ng WL, Collins PF, Hickling DF and Bell JJ: Evaluating the concurrent validity of body mass index (BMI) in the identification of malnutrition in older hospital inpatients. Clin Nutr Edinb Scotl, 2018. PMID: 30501917. DOI: 10.1016/ j.clnu.2018.10.025

10 Büntzel J, Putziger J, Büntzel H, Gäbert $\mathrm{J}$ and Oehler W: Ernährungsmedizinische Diagnostik für HNO-Tumorpatienten: eine kritische Analyse. M0109; 81. Jahresverdammlung der Deutschen Gesellschaft für Hals-Nasen-Ohren-Heilkunde, Kopfund Hals-Chirurgie; Wiesbaden, DOI: 10.3205/10hno142

11 Ebner $\mathrm{N}$ and Haehling S von: Kachexie und sarkopenie bei chronischer herzinsuffizienz. Internist 59: 439-444, 2018. PMID: 29637239. DOI: $10.1007 / \mathrm{s} 00108-018-0408-3$

12 Universitätsklinikum Halle(Saale): Excel ${ }^{\circledR}$ _Tools. Available from: https://www.medizin.uni-halle.de/index.php?id=1358 [last accessed February 10, 2019].

13 Arends J, Baracos V, Bertz H, Bozzetti F, Calder PC, Deutz NEP, Erickson N, Laviano A, Lisanti MP, Lobo DN, McMillan DC, Muscaritoli M, Ockenga J, Pirlich M, Strasser F, de van der Schueren M, Van Gossum A, Vaupel P and Weimann A: ESPEN expert group recommendations for action against cancer-related malnutrition. Clin Nutr Edinb Scotl 36: 1187-1196, 2017. PMID: 28689670. DOI: 10.1016/j.clnu.2017.06.017

14 Chen L-K, Liu L-K, Woo J, Assantachai P, Auyeung T-W, Bahyah KS, Chou M-Y, Chen L-Y, Hsu P-S, Krairit O, Lee JSW, Lee W-J, Lee Y, Liang C-K, Limpawattana P, Lin C-S, Peng L-N, Satake S, Suzuki T, Won CW, Wu C-H, Wu S-N, Zhang T, Zeng P, Akishita $\mathrm{M}$ and Arai H: Sarcopenia in Asia: consensus report of the Asian Working Group for Sarcopenia. J Am Med Dir Assoc 15: 95-101, 2014. PMID: 24461239. DOI: 10.1016/j.jamda.2013.11.025
15 Cruz-Jentoft AJ, Baeyens JP, Bauer JM, Boirie Y, Cederholm T, Landi F, Martin FC, Michel J-P, Rolland Y, Schneider SM, Topinková E, Vandewoude M, Zamboni M and European Working Group on Sarcopenia in Older People: Sarcopenia: European consensus on definition and diagnosis: Report of the European Working Group on Sarcopenia in Older People. Age Ageing 39: 412-423, 2010. PMID: 20392703. DOI: 10.1093/ageing/afq034

16 Fearon K, Strasser F, Anker SD, Bosaeus I, Bruera E, Fainsinger RL, Jatoi A, Loprinzi C, MacDonald N, Mantovani G, Davis M, Muscaritoli M, Ottery F, Radbruch L, Ravasco P, Walsh D, Wilcock A, Kaasa $\mathrm{S}$ and Baracos VE: Definition and classification of cancer cachexia: an international consensus. Lancet Oncol 12: 489-495, 2011. PMID: 21296615. DOI: 10.1016/S1470-2045(10)70218-7

17 Kumar S, Dutt A, Hemraj S, Bhat S and Manipadybhima B: Phase Angle Measurement in Healthy Human Subjects through Bio-Impedance Analysis. Iran J Basic Med Sci 15: 1180-1184, 2012. PMID: 23653848.

18 Büntzel J, Büntzel H, Micke O, Mücke R, Kisters K, Hübner J, Schäfer U, Boehme R and Oehler W: Nutritional support for head and neck cancer patients before irradiation - a pilot project for malnutrition risk group. Trace Elem Electroly 31: 1-5, 2014. DOI: 105414TEX01310, 5414.

19 Mullie L, Obrand A, Bendayan M, Trnkus A, Ouimet M-C, Moss E, Chen-Tournoux A, Rudski LG and Afilalo J: Phase angle as a biomarker for frailty and postoperative mortality: The BICS Study. J Am Heart Assoc 7: e008721, 2018. PMID: 30371163. DOI: $10.1161 /$ JAHA.118.008721

20 Pérez Camargo DA, Allende Pérez SR, Verastegui Avilés E, Rivera Franco MM, Meneses García A, Herrera Gómez Á and Urbalejo Ceniceros VI: Assessment and impact of phase angle and sarcopenia in palliative cancer patients. Nutr Cancer 69: 1227-1233, 2017. PMID: 29083245. DOI: 10.1080/01635581.2017.1367939

21 Axelsson L, Silander E, Bosaeus I and Hammerlid E: Bioelectrical phase angle at diagnosis as a prognostic factor for survival in advanced head and neck cancer. Eur Arch Otorhinolaryngol 275: 2379-2386, 2018. PMID: 30046911. DOI: 10.1007/s00405-018-5069-2

22 Büntzel J, Krauß T, Büntzel H, Küttner K, Fröhlich D, Oehler W, Glatzel M, Wackes M, Putziger J, Micke O, Kisters K and Mücke R: Nutritional parameters for patients with head and neck cancer. Anticancer Res 32: 2119-2123, 2012. PMID: 22593498.

Received February 14, 2019 Revised March 10, 2019 Accepted March 12, 2019 